\title{
REMOÇÃO DO ÓLEO DA ÁGUA PRODUZIDA UTILIZANDO O CARVÃO ATIVADO COMERCIAL
}

\author{
D.A. ARAÚJO ${ }^{1}$, F.D.S. CURBELO ${ }^{1}$, R.M. BRAGA ${ }^{2}$, A.I.C. GARNICA ${ }^{1}$ \\ ${ }^{1}$ Universidade Federal da Paraíba, Centro de Tecnologia, Departamento de Engenharia Química \\ ${ }^{2}$ Universidade Federal do Rio Grande do Norte, Escola Agrícola de Jundiaí \\ dimitriaraujo@icloud.com
}

Submetido 20/04/2017 - Aceito 05/12/2017

DOI: $10.15628 /$ holos.2017.5891

\section{RESUMO}

Nas atividades de produção e exploração de óleo e gás são gerados resíduos e efluentes, dentre os quais se destaca a água produzida, que vem junto com o petróleo e o gás. Esta precisa ser tratada para ser descartada ou reinjetada nos poços de petróleo. Neste sentido, este trabalho teve como objetivo principal estudar o processo de remoção do óleo da água produzida por adsorção utilizando carvão ativado comercial. Os dados de equilíbrio do sistema foram obtidos pelo método do banho finito, em que massas conhecidas de carvão foram postas em contato com água produzida sintética a temperatura constante $(25 \stackrel{\circ}{\circ})$ durante um tempo de 5 horas. A curva de ruptura foi determinada em coluna de leito fixo e os modelos cinéticos de Thomas e Yoon-Nelson foram utilizados para validar a mesma. Os resultados mostraram que a isoterma de Freundlich representou satisfatoriamente os dados de equilíbrio. A capacidade adsortiva obtida na coluna foi igual a 442,34 mg de óleo/g de carvão. A capacidade adsortiva para isoterma de Freundlich foi igual a $389,06 \mathrm{mg} / \mathrm{g}$ e para os modelos de Thomas e YoonNelson foram 410,30 mg/g e 410,28 mg/g, respectivamente. A proximidade destes valores garante uma coerência em relação ao fenômeno de transferência de massa ocorrido para o sistema estudado. Consequentemente, essa proximidade valida os dados de equilíbrio e a curva de ruptura. $\mathrm{O}$ ponto de ruptura foi fixado no ponto $\mathrm{C} / \mathrm{C}_{0}=30 \%$, com tempo de ruptura tb de $5580 \mathrm{~s}$ e porcentagem de leito não utilizado de $12,90 \%$. Nestas condições a remoção contínua de óleo, na água produzida, foi de aproximadamente $90 \%$ até a interrupção da operação.

PALAVRAS-CHAVE: adsorção, água produzida, leito fixo, curva de ruptura.

\section{OIL REMOVAL FROM PRODUCED WATER USING COMMERCIAL ACTIVATED CARBON.}

\begin{abstract}
In the oil and gas exploration, many effluents are generated, among which the produced water, that must be treated for disposal or reinjection into the oil wells. Thus, main objective of this work was to study oil removal process from produced water by adsorption using commercial activated carbon. The equilibrium data of the system were obtained from bath, where known carbon weight were brought into contact with produced water at constant temperature $\left(25^{\circ} \mathrm{C}\right)$ during 5 hours. The breakthrough curve was determined in a fixed bed column and Thomas and Yoon-Nelson kinetic models were used to validate this. The equilibrium data was satisfactorily represented by Freundlich isotherm.
\end{abstract}

The adsorptive capacity obtained in the column was $442.34 \mathrm{mg}$ of oil/g of carbon. The adsorptive capacity for Freundlich isotherm was $389.06 \mathrm{mg} / \mathrm{g}$ and for the Thomas and Yoon-Nelson models were $410.30 \mathrm{mg} / \mathrm{g}$ and $410.28 \mathrm{mg} / \mathrm{g}$, respectively. The proximity of these results guarantees a coherence in relation to the mass transfer phenomenon occurred in this system. Consequently, this closeness validates equilibrium data and breakthrough curve. Break point of $\mathrm{C} / \mathrm{C}_{0}=30 \%$ was fixed, at break time tb of $5580 \mathrm{~s}$ and unused bed length fraction of $12.90 \%$. Under these conditions, continuous oil removal in produced water was approximately $90 \%$ until interruption of the operation.

KEYWORDS: adsorption, produced water, fixed bed, breathrough curve. 


\section{INTRODUÇÃO}

A crescente conscientização ambiental, associada a um maior rigor nas legislações vigentes, tem contribuído significativamente para a implantação de estações de tratamento de efluentes como uma etapa obrigatória no ciclo produtivo dos processos industriais, independente da área de atuação. Não importando o processo utilizado, um dos problemas mais comuns observados na maioria das estações de tratamento industriais é a adequação da qualidade dos efluentes a serem descartados nos corpos receptores, principalmente no que se refere aos elevados teores de óleos e graxas. Isso acarreta em problemas com a disposição no ambiente, o que abre espaço para a introdução de novos processos de tratamento.

Nas atividades de produção e exploração de óleo e gás são gerados resíduos e efluentes, dentre os quais se destaca a água produzida, que vem junto com o petróleo e o gás. Ela consiste na água de formação, que é naturalmente presente na formação geológica do reservatório de petróleo, e na água de injeção, que é aquela injetada no reservatório para aumento da produção. Geralmente os campos no início da produção geram pequenas quantidades de águas, que aumentam no decorrer do tempo e atingem valores próximos a $90 \%$ quando o campo se encontra no seu estágio final de produção econômica (Ray e Engelhardt, 1992).

A água produzida pode ser descartada em corpos receptores ou ser utilizada na injeção de poços de petróleo. Porém, para essa disposição, faz-se necessário o tratamento correto. No caso do descarte em corpos receptores o limite é de até $20 \mathrm{mg}$. $\mathrm{L}^{-1}$ de teor de óleo e graxas (TOG) na água produzida, segundo a Resolução 357/2005 do Conselho Nacional de Meio Ambiente (CONAMA, 2005). Para o descarte em plataformas marítimas de petróleo, aplica-se a Resolução 393/2007 do CONAMA, que estabelece a média aritmética simples mensal de teor de óleos e graxas de até $29 \mathrm{mg} \cdot \mathrm{L}^{-1}$, com valor máximo diário de $42 \mathrm{mg} \cdot \mathrm{L}^{-1}$. Para injeção em poços de petróleo, a água deverá ter no máximo $5 \mathrm{mg} \cdot \mathrm{L}^{-1}$ de TOG (CONAMA, 2007; Santiago, 2009).

Os hidrociclones e a flotação são os processos de separação óleo/água mais utilizados pela indústria do petróleo. A flotação procura recuperar o resíduo de óleo através de separação gravitacional, enquanto os hidrociclones aceleram esse processo através da força centrífuga (Thomas, 2004).

O carvão ativado é amplamente utilizado no tratamento de efluentes. Obtido geralmente a partir de materiais lignocelulósicos, como madeiras, casca de coco, de arroz, bagaço de canade-açúcar e entre outros, o carvão ativado possui um grande desenvolvimento poroso que o permite ser um dos adsorventes mais versáteis já utilizados (Oliveira et al., 2014). Apesar do seu amplo uso, pesquisas envolvendo a remoção de óleos e graxas da água produzida usando o carvão ativado são recentes e promissoras (Okiel et al., 2011; Oliveira et al., 2014).

Portanto, o objetivo geral deste trabalho foi investigar a viabilidade e o potencial do carvão ativado comercial para a remoção do óleo presente nas águas produzidas da indústria petrolífera. 


\section{REVISÃO BIBLIOGRÁFICA}

\section{1 Água Produzida}

A origem da água produzida se relaciona com a origem do petróleo. Ela pode estar relacionada ou não à formação geológica do reservatório produtor de petróleo. Um ambiente geológico no qual tenha ocorrido intensa deposição de matéria orgânica, associada com um posterior soterramento e condições físico-químicas adequadas, são fatores que podem levar ao aparecimento de petróleo nas rochas matrizes. O petróleo gerado migra por rochas permeáveis até encontrar armadilhas formadas por rochas impermeáveis que o retém. Com o passar de milhares de anos, o petróleo se concentra nessas regiões e segregam-se da água dos aquíferos, porém o óleo e a água continuam em contato (Santiago, 2009).

A denominação de água produzida pode ser dada à água contida originalmente no reservatório e à água injetada durante o processo produtivo (Nunes, 2013). Em poços que operam com recuperação secundária a partir da injeção de água é comum se produzir parte da água utilizada. Isso acarreta em grandes volumes de água produzida que devem ser descartados após o correto tratamento (Oliveira e Oliveira, 2013).

Na maioria dos poços recém-abertos, a produção da água original, chamada de conata, é pequena. Com o avançar da produção, a pressão no interior do reservatório diminui, o que altera o nível de contato entre o óleo e a água conata. Esse aumento de contato em conjunto com a agitação dos fluidos devido às suas migrações dentro do reservatório permite a solubilização e dispersão de alguns hidrocarbonetos na água, elevando as quantidades de emulsões. Essas emulsões são constituídas pela fase dispersa, que é o óleo na forma de gotículas, e pela fase contínua, que é a água (ARPEL, 2005).

Em 2009, a estimativa global de produção de água estava na ordem de 250 milhões de barris/dia, enquanto que a de óleo estava na ordem de 80 milhões de barris/dia. De modo geral, a proporção água/óleo era de aproximadamente 3:1 (Carvalho, 2016). De acordo com Thomas (2004), a proporção água/óleo de fato varia entre 3:1 a 4:1, podendo chegar até 7:1 em alguns casos específicos.

No ano de 2013, as operações offshore no Brasil registraram aproximadamente 95 milhões de $\mathrm{m}^{3}$ de água produzida, enquanto que a quantidade de óleo produzida foi de 107 milhões de $\mathrm{m}^{3}$, o que gera uma relação água/óleo de 0,89:1 (Morais, 2013). A diferença entre a média brasileira e a mundial se deve à recente exploração offshore brasileira se comparada com o resto do mundo, onde os poços se encontram mais maduros.

Comumente, apenas leva-se em consideração na escolha do processo de tratamento e do local de descarte adequado a salinidade da água produzida e o teor de óleos e graxas (TOG). Em 1993, a agência de proteção ao meio ambiente dos EUA (Environmental Protection Agency-EPA) estabeleceu novos limites para o TOG livres para o descarte de águas produzidas em ambiente offshore (Oliveira e Oliveira, 2013). Em termos de legislação, existem muitas diferenças a nível mundial para o TOG permitido para o descarte de águas produzidas. De modo geral, a maioria dos países estabeleceram que a média mensal é de $40 \mathrm{mg} \cdot \mathrm{L}^{-1}$ e o valor máximo permitido para descarte é de $100 \mathrm{mg} . \mathrm{L}^{-1}$ (Santiago, 2009). Recentemente na Convenção de Paris, que teve como 
foco a prevenção de poluição marinha a partir de fontes baseadas em terra, reduziu-se o limite de TOG livre médio mensal de $40 \mathrm{mg} \cdot \mathrm{L}^{-1}$ para $30 \mathrm{mg} \cdot \mathrm{L}^{-1}$ nos oceanos Ártico e Atlântico Nordeste (Oliveira e Oliveira, 2013).

No Brasil, têm-se duas perspectivas diferentes acerca do descarte da água produzida. Para o descarte em corpos receptores, o limite é de $20 \mathrm{mg} \cdot \mathrm{L}^{-1}$ de TOG na água produzida, de acordo a Resolução 357/2005 do CONAMA. Para o descarte em plataformas marítimas de petróleo, a resolução vigente é a 393/2007 do CONAMA, que estabelece a média aritmética simples mensal de TOG de até $29 \mathrm{mg} \cdot \mathrm{L}^{-1}$, com valor máximo diário de $42 \mathrm{mg} \cdot \mathrm{L}^{-1}$. Para injeção em poços de petróleo, a água deverá ter no máximo $5 \mathrm{mg} \cdot \mathrm{L}^{-1}$ de TOG (Santiago, 2009).

\subsection{Carvão Ativado}

O carvão ativado é um dos adsorventes mais utilizados mundo a fora no tratamento de água e de rejeitos aquosos. Pode-se dizer que o carvão, sem ativação, era utilizado por Scheele desde 1773 no tratamento de gases. O mesmo também se utilizou do carvão in natura para descolorir soluções aquosas em 1786 e foi o responsável por realizar a primeira quantificação do poder adsortivo do carvão em fase líquida (Bhatnagar et al., 2013).

O carvão ativado comercialmente viável surgiu no início do século XX com o cientista sueco von Ostreijko, que obteve duas patentes em 1900 e em 1901. Essas patentes continham os conceitos básicos acerca da ativação química e física, essa última também chamada de termal (Bhatnagar et al., 2013). A partir daí, pesquisas envolvendo diferentes métodos de ativação do carvão foram desenvolvidas.

O carvão ativado geralmente é elaborado a partir da decomposição térmica da matéria orgânica, seguido pelo processo de ativação, que pode ser física ou química. Em um primeiro momento, as principais matérias-primas utilizadas na elaboração do carvão ativado eram carvão natural, madeiras e resíduo da indústria do petróleo (Boligon, 2015; Werlang et al., 2013). Atualmente, o carvão ativado é preparado por meio da pirólise oxidativa com a utilização de madeiras macias e duras, turfa, linhita, carvão mineral, casca de coco e resíduos de origem vegetal (Araújo, 2015; Gonçalves, 2008; Hernández e Bonilla, 2012).

Os carvões ativados podem ser classificados de acordo com o tamanho dos poros existentes. Os carvões macroporosos são aqueles que possuem diâmetro de poro maior que 50 $\mathrm{nm}$, mesoporosos aqueles que possuem diâmetro de poro entre 2 e $50 \mathrm{~nm}$ e microporosos aqueles que possuem diâmetro de poro menor que $2 \mathrm{~nm}$. É valido ressaltar que qualquer carvão ativado possui todos os tipos de poros, porém sempre há uma variação na sua proporção relativa, de acordo com o precursor e o processo de elaboração, síntese e ativação, utilizado (Crispim, 2009).

Estudos envolvendo a utilização do carvão ativado para a remoção de óleo da água produzida são recentes. Originalmente, o carvão ativado é utilizado no tratamento da água produzida para a remoção de compostos orgânicos dissolvidos, de metais pesados e de BTEX (benzeno, tolueno, etilbenzeno e xileno) (Ferreira, 2016).

De acordo com a Agência de Proteção Ambiental dos Estados Unidos (EPA), o carvão ativado é classificado como uma das melhores tecnologias para a remoção de contaminantes orgânicos, dentre eles óleos e graxas contidas na água produzida (Okiel et al., 2011; Oliveira et 
al., 2014). Com isso, o carvão ativado se credencia como um potencial removedor de óleos e graxas da água produzida.

Os resultados mostrados por Okiel et al. (2011) evidenciam que o carvão ativado comercial em pó utilizado removeu pelo menos $80 \%$ do óleo contido em uma amostra real de água produzida de uma empresa local, o que mostra o seu potencial de utilização como adsorvente de matéria orgânica.

\subsection{Adsorção}

A adsorção é um processo de transferência de um ou mais constituintes de uma fase fluida para a superfície de uma fase sólida. Atualmente, a adsorção é definida como um fenômeno de superfície no qual uma concentração finita de moléculas de um fluido, por afinidade, adere a uma superfície devido a um não balanceamento de forças. Os principais elementos da adsorção são o fluido (adsortivo), a superfície na qual o fenômeno ocorre (adsorvente) e os componentes retidos pela superfície (adsorbato) (Dabrowski, 2001). Os dois tipos principais de adsorção são a física e a química (Castellan, 1978).

A adsorção física é um processo reversível no qual uma molécula entra em contato com a superfície do meio filtrante e adere a ela através de forças mecânicas. A energia, por exemplo a cessão de calor, pode causar às moléculas o desligamento da superfície do meio filtrante. Dessa maneira, o meio filtrante pode ser regenerado e reusado.

$\mathrm{Na}$ adsorção física, os efeitos atrativos que ocorrem entre o adsorvente e o adsorbato são relativamente fracos, envolvendo, principalmente, interações eletrostáticas e de Van der Waals, o que compreende as interações de polarização, tipo dipolos permanente, dipolos induzido e quadrupolo. As contribuições de Van der Waals estão sempre presentes, enquanto as contribuições eletrostáticas são significantes apenas no caso de adsorventes que possuem uma estrutura iônica, tais como zeólitas (Ruthven, 1984).

A energia liberada quando uma espécie é adsorvida fisicamente é da mesma ordem de grandeza da entalpia de condensação de moléculas (1 a $5 \mathrm{~kJ} \cdot \mathrm{mol}^{-1}$ ) (Ruthven, 1984). A pequena variação da entalpia é insuficiente para resultar em uma quebra de ligação, portanto uma espécie fisissorvida preserva sua identidade química, sendo assim, esse tipo de adsorção tem caráter não específico. Essa propriedade indica que o mesmo fenômeno pode ser observado para diferentes adsorbatos, sendo necessário que apresente apenas dipolo induzido (Ruthven, 1984). A adsorção física é do tipo não localizada, ou seja, as moléculas adsorvidas podem se movimentar livremente sobre a superfície do adsorvente.

No caso da adsorção química, ou quimissorção, tem-se um compartilhamento ou uma troca de elétrons entre o adsorvente e o adsorbato. Esse fenômeno faz com que a adsorção perca suas características puramente físicas, passando a haver ligações covalentes ou iônicas entre os constituintes do processo adsortivo. Pode-se dizer que as energias envolvidas durante o processo de quimissorção se aproximam de valores observados em reações químicas.

O processo de adsorção pode ser influenciado por vários fatores, tais como: temperatura, natureza e concentração do adsorbato, natureza do adsorvente e seu estado de agregação, pH, tamanho de partícula, tempo de contato e velocidade de agitação (Shukla et al., 2002).

Experimentalmente, um sistema adsorbato-adsorvente é considerado em equilíbrio quando, por maior que seja o tempo de contato entre o adsorvente e a espécie a ser adsorvida, não há variação na concentração da fase fluida. Este equilíbrio de fases pode ser representado 
por isotermas de adsorção, ou seja, curvas a temperatura constante que relacionam os dados entre a concentração do adsorbato e a massa do adsorvente.

Um dos modelos adsortivos mais estudados é o proposto por Langmuir (1918). Este considera a formação de uma única camada sobre o adsorvente, podendo também existir a formação de multicamadas através dos mecanismos de evaporação e condensação. $A$ isoterma de Langmuir corresponde a um tipo altamente idealizado na qual são feitas as seguintes hipóteses:

- As moléculas são adsorvidas em pontos discretos da superfície que são chamados "sítios de adsorção";

- Cada sítio pode acomodar somente uma entidade adsorvida (adsorção em monocamada).

- A energia da espécie adsorvida é a mesma em qualquer ponto da superfície e é independente da presença ou ausência de moléculas adsorvidas na vizinhança, ou seja, a superfície é completamente uniforme sob o ponto de vista energético.

- A adsorção é localizada e ocorre por colisão de moléculas com sítios disponíveis.

A Equação 1 é comumente denominada de Equação de Langmuir e é utilizada nos casos no qual se considera o equilíbrio de adsorção e dessorção física em monocamada:

$$
q_{e}=\frac{K_{L} C_{e} q_{m}}{1+K_{L} C_{e}}
$$

Em que $\mathrm{q}_{\mathrm{e}}(\mathrm{mg} / \mathrm{g})$ corresponde à massa do soluto adsorvida por unidade de massa do adsorvente no equilíbrio; $C_{e}(\mathrm{mg} / \mathrm{L})$, a concentração de equilíbrio do adsorbato na fase fluida; $K_{L}$ ( $\mathrm{L} / \mathrm{mg}$ ) é a constante de equilíbrio relacionada com a energia de ligação adsorbato-adsorvente; $\mathrm{q}_{\mathrm{m}}(\mathrm{mg} / \mathrm{g})$ é constante que representa a quantidade máxima de adsorbato que pode ser adsorvida. A determinação das constantes $\mathrm{K}_{\mathrm{L}}$ e $\mathrm{q}_{\mathrm{m}}$ podem ser realizadas a partir de uma regressão não-linear, de modo a adequar o modelo aos valores experimentais.

Dentre os modelos de adsorção clássicos, a equação de Freundlich foi uma das primeiras equações propostas para estabelecer uma relação entre a quantidade de material adsorvido e a concentração do material na solução (Araújo e Sobrinho, 2000). Este modelo não considera a equivalência energética dos sítios de adsorção, admitindo que o processo de adsorção apresenta uma distribuição exponencial de calores de adsorção a partir da monocamada adsorvida e pode assim ser representado:

$$
q_{e}=K_{F} C_{e}^{1 / n}
$$

Em que $\mathrm{q}_{\mathrm{e}}(\mathrm{mg} / \mathrm{g})$ e $\mathrm{C}_{\mathrm{e}}(\mathrm{mg} / \mathrm{L})$ têm o mesmo significado daqueles já definido para a isoterma de Langmuir, $\mathrm{K}_{\mathrm{F}}$ (L/g) e $\mathrm{n}$ (adimensional) são respectivamente constantes empíricas indicadoras da capacidade e intensidade da energia de adsorção (LeVan et al., 2007). Do mesmo modo, pode- 
se determinar os parâmetros $\mathrm{n}$ e $\mathrm{K}_{\mathrm{F}}$ a partir de uma regressão não-linear. $\mathrm{O}$ valor de $\mathrm{n}$ é sempre maior que 1; quando se encontra no intervalo entre 1 e 10 é um indicativo da natureza favorável da adsorção (Erdem et al., 2004).

\subsubsection{Adsorção em leito fixo}

$\mathrm{Na}$ adsorção em leito fixo a concentração da fase fluida muda de acordo com o tempo e com a posição na coluna. A região onde está ocorrendo a transferência de massa em função do tempo é chamada de ZTM (Zona de Transferência de Massa) e a suas características dependem de alguns fatores, como diâmetro da coluna, adsorvente utilizado, fase fluida utilizada e entre outros (McCabe et al., 1993).

A capacidade adsortiva de um leito fixo $q_{\text {col }}(\mathrm{mg} / \mathrm{g})$ é estimada através das curvas de ruptura (breakthrough curves), como mostrado na Figura 1. Considerando uma solução binária, gasosa ou líquida, que contém um soluto com concentração $C_{0}(\mathrm{mg} / \mathrm{L})$; o fluido passará continuamente no sentido descendente através de um leito de adsorvente suficientemente profundo, inicialmente livre do adsorbato.

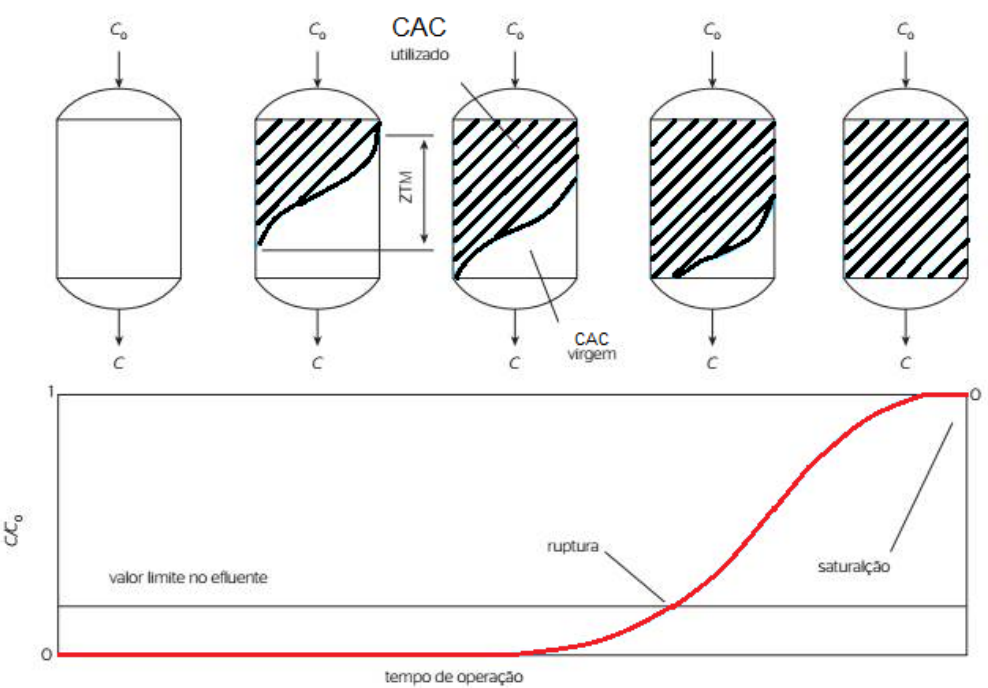

Figura 1: Curva de ruptura para a adsorção em leito fixo (VOLTAN et al., 2016 - Adaptado)

Em que CAC representa o adsorvente, que neste estudo foi um carvão ativo comercial (CAC).

A camada superior da coluna, em contato com a solução concentrada, primeiramente adsorve soluto de maneira rápida e efetiva; A pequena quantidade de soluto que permanece na solução é totalmente removida pelas camadas inferiores do leito. $O$ efluente no final do leito é praticamente livre de soluto e apresenta uma concentração muito próxima de zero (McCabe et al., 1993). O avanço gradativo da ZTM é indicada na parte superior da Figura 1.

A camada superior do leito é praticamente saturada, enquanto que na ZTM há uma mudança brusca de concentração do adsorbato no fluido. Se a solução continuar a fluir, a ZTM se move para baixo como uma onda, a uma taxa mais baixa do que a velocidade linear do fluido através do leito. Posteriormente, a ZTM se aproxima da base da coluna, porém a concentração do efluente continua aproximadamente zero (McCabe et al., 1993). 
Quanto a ZTM atinge a base da coluna, a concentração do efluente começa a se elevar rapidamente. Nesse ponto, diz-se que o sistema atingiu a ruptura.

A concentração do soluto no efluente sobe rapidamente se a ZTM passar no final do leito e atinge subitamente o valor inicial " $\mathrm{C}_{0}$ ". A parte da curva de formato ondulatório é denominada curva de abertura. A ZTM, onde grande parte das mudanças na concentração ocorre, possui comumente limites que vão de $C / C_{0}$ de 0,10 até 0,95 . Se a solução continua a fluir, apenas uma pequena adsorção adicional ocorre, já que o leito está praticamente em total equilíbrio com a solução de alimentação (McCabe et al., 1993).

O momento do aparecimento da curva de ruptura e sua forma influenciam muito no método de operação de um adsorvedor de leito fixo. As curvas de ruptura, geralmente, têm forma de "S", podem ser achatadas ou terem forma de degraus e, em alguns casos, podem ser deformadas. Se o processo de adsorção for infinitamente rápido, na parte inferior da Figura 1, a curva de ruptura será uma linha vertical reta (McCabe et al., 1993). A taxa real e o mecanismo do processo de adsorção, a natureza do equilíbrio de adsorção, a velocidade do fluido, a concentração de soluto na alimentação e o comprimento do leito adsorvente (particularmente, para uma concentração de soluto na alimentação alta) contribuem para a forma da curva produzida (LeVan et al., 2007).

O método de análise das curvas de ruptura baseia-se em balanços materiais globais. $O$ cálculo da área entre a curva de ruptura e a reta $\mathrm{C} / \mathrm{C}_{0}=1$ pode ser usado para a determinação da capacidade do leito, capacidade não utilizada, volume estequiométrico e velocidade média do leito saturado. Essa região pode ser calculada também a partir da área retangular em um tempo $t^{*}$, no qual considera-se um processo adsortivo extremamente rápido, o que produz uma curva de ruptura no formato de uma reta, ao invés do comum formato de $\mathrm{S}$. Na maioria dos casos, o tempo $t^{*}$ compreende o tempo no qual atingiu-se a concentração $C / C_{0}=0,5$ (McCabe et al., 1993).

A partir de um balanço material simples, considera-se que a taxa de alimentação do soluto por unidade de área transversal do leito $F_{A}$ é igual a multiplicação entre a velocidade superficial $\mu_{0}$ e a concentração de entrada do adsorbato $C_{0}$ :

$$
F_{A}=\mu_{0} C_{0}
$$

Ainda considerando a idealidade, o soluto que entra na coluna até o tempo t* é adsorvido e a concentração de adsorbato no adsorvente atinge o equilíbrio. Com isso, tem-se:

$$
\begin{gathered}
\mu_{0} C_{0} t^{*}=h \rho_{b}\left(q_{C O L}-q_{0}\right) \\
t^{*}=\frac{h \rho_{b}\left(q_{C O L}-q_{0}\right)}{\mu_{0} C_{0}}
\end{gathered}
$$


Em que $\mathrm{h}(\mathrm{cm})$ é o comprimento do leito, $\rho_{\mathrm{b}}\left(\mathrm{g} / \mathrm{cm}^{3}\right)$ é a densidade aparente do leito, $\mathrm{q}_{0}$ $(\mathrm{mg} / \mathrm{g})$ é a capacidade adsortiva inicial do leito, $\mathrm{q}_{\mathrm{cos}}(\mathrm{mg} / \mathrm{g})$ é a capacidade adsortiva final do leito, $\mu_{0}(\mathrm{~cm} / \mathrm{s})$ é a velocidade superficial, $C_{0}\left(\mathrm{mg} / \mathrm{cm}^{3}\right)$ é a concentração inicial da fase fluida e $t^{*}$ (s) é o tempo de ruptura ideal.

De modo geral, o tempo de ruptura real $t_{b}$ é sempre menor do que o tempo de ruptura ideal t*. O quão afastado serão esses tempos dependerá da forma no qual a curva de ruptura se apresenta, ou seja, quanto mais sinuosa e espaçada for a curva de ruptura, maior será a distância entre os tempos e, consequentemente, menor será a fração de leito utilizado no processo (McCabe et al., 1993).

A porcentagem de leito não utilizado "LUB" é um parâmetro importante na interpretação da eficiência do sistema montado. Ele fornecerá a proporção de leito que não será utilizado no processo adsortivo, visto que a operação é interrompida quando se atinge uma concentração de saída limite do efluente tratado na coluna. Quanto mais achatada for a curva de ruptura do sistema, menor será o LUB e, consequentemente, quanto mais espaçada for, maior será o LUB.

Portanto, para calcular a porcentagem de leito não utilizado "LUB" tem-se:

$$
L U B=\left(\frac{V_{S A T}-V_{R U P}}{V_{S A T}}\right) * 100 \%
$$

Em que LUB é a porcentagem de leito não utilizado, $V_{S A T}$ é o volume de efluente tratado após a completa saturação do leito e $V_{R U P}$ é o volume de efluente tratado no momento de aferição da concentração limite estipulada para a interrupção de funcionamento da coluna.

Com a proporção de leito não utilizado da coluna, pode-se calcular o tempo de ruptura tb a partir da relação:

$$
t_{b}=t^{*} *\left(1-\frac{L U B}{100 \%}\right)
$$

Em que tb é o tempo de ruptura, $t^{*}$ é o tempo de ruptura ideal e LUB é comprimento de leito não utilizado em porcentagem.

\subsubsection{Modelagem matemática}

A dinâmica do processo adsortivo em leito fixo pode ser, por vezes, de difícil previsão devido aos diferentes fenômenos que ocorrem simultaneamente à transferência de massa, além de uma considerável variação de concentração do adsorbato em regiões específicas do fluido e do adsorvente (Canteli, 2013; Oliveira, 2014).

A modelagem matemática, nesse caso, tem como papel principal fornecer uma predição do comportamento de um sistema com o mesmo conjunto adsorbato-adsorvente, porém com 
dimensões de coluna e condições de operação mais flexíveis. Os modelos matemáticos podem ser validados a partir de dados experimentais obtidos em menor escala (Oliveira, 2014).

De maneira geral, esses modelos descrevem o processo de adsorção em leito fixo como tendo apenas uma etapa limitante, o que reduz a quantidade de equações e, consequentemente, a complexidade da problemática. Soluções numéricas e analíticas podem ser utilizadas pelos modelos, a depender da complexidade de resolução (Oliveira, 2014; Tien, 1994).

\subsubsection{Modelo de Thomas}

O modelo adsortivo descrito por Thomas é um dos principais modelos utilizados na predição da capacidade adsortiva do adsorvente e das curvas de ruptura de diversos conjuntos adsorbatoadsorvente (Xu et al. , 2013). Este assume condições cinéticas e fenomenológicas específicas que simplificam o equacionamento do processo adsortivo (El-Naas et al., 2017).

Thomas (1944) assume que as propriedades físicas do adsorbato e do adsorvente se mantém constantes durante o processo, assim como as condições de temperatura e de pressão. A difusão intra-partícula e a resistência externa à transferência de massa são consideradas de pouca relevância; o mesmo vale para a dispersão axial e radial na coluna. A isoterma de adsorção que representa o equilíbrio é descrito pelo modelo de Langmuir e a cinética de adsorção é descrita por uma reação de pseudo-segunda ordem.

Uma observação importante acerca do modelo de Thomas é de que o equacionamento pode não ser representativo para sistemas que se utilizem de baixos fluxos ou concentrações de entrada do adsorbato muito pequenas (El-Naas et al., 2017; Oliveira, 2014; Xu et al., 2013).

A Equação 8 expressa o modelo proposto por Thomas (1944):

$$
\frac{C}{C_{0}}=\frac{1}{1+\exp \left[\left(\frac{K_{T H} q_{T H} m}{Q}\right)-K_{T H} C_{0} t\right]}
$$

Em que $\mathrm{C} / \mathrm{C}_{0}$ (adimensional) é a relação entre as concentrações de saída e de entrada da coluna, $\mathrm{K}_{\mathrm{TH}}\left(\mathrm{L} \mathrm{mg}^{-1} \mathrm{~s}^{-1}\right)$ é a constante cinética de Thomas, $\mathrm{q}_{\mathrm{TH}}(\mathrm{mg} / \mathrm{g})$ é a capacidade adsortiva do adsorvente, $\mathrm{m}(\mathrm{g})$ é a massa de adsorvente utilizada, $\mathrm{Q}(\mathrm{L} / \mathrm{s})$ é a vazão volumétrica de efluente na coluna e $t$ (s) é o tempo de operação. Para a obtenção dos parâmetros inerentes ao modelo, $\mathrm{K}_{\mathrm{TH}}$ e $q_{T H}$, realiza-se uma regressão não-linear com os pontos experimentais contidos na região de ruptura da coluna.

\subsubsection{Modelo de Yoon-Nelson}

O modelo de Yoon-Nelson possui uma forma bastante resumida. A sua principal consideração é a de que a diminuição da probabilidade de cada molécula do adsorbato ser adsorvida é proporcional à probabilidade de sua adsorção e ruptura no adsorvente (Canteli, 2013; El-Naas et al., 2017; Xu et al., 2013). A principal vantagem deste modelo é não necessitar de dados específicos do sistema, como características do adsorbato e do adsorvente e as propriedades físicas do leito adsortivo (Oliveira, 2014). 
O modelo determina o tempo necessário para que o adsorvente sature $50 \%$ do leito " $\tau$ ", que também é o tempo de ruptura ideal descrito como $t^{*}$, a constante cinética de Yoon-Nelson $\mathrm{K}_{\mathrm{YN}}$ e a capacidade adsortiva do conjunto adsorbato-adsorvente.

A Equação 9 descreve o modelo proposto por Yoon e James (1984):

$$
\frac{C}{C_{0}}=\frac{1}{1+\exp \left[K_{Y N}(\tau-t)\right]}
$$

Em que $C / C_{0}$ (adimensional) é a relação entre as concentrações de saída e de entrada da coluna, $\mathrm{K}_{\mathrm{YN}}\left(\mathrm{s}^{-1}\right)$ é a constante cinética de Yoon-Nelson, $\tau$ (s) é o tempo para a coluna atingir $50 \%$ da saturação e $t$ (s) é o tempo do processo adsortivo.

Para o cálculo da capacidade adsortiva do adsorvente, tem-se a consideração de que a quantidade de adsorbato adsorvida é a metade do total de adsorbato que entra na coluna em um período de tempo $2 \tau$ (Oliveira, 2014). Portanto, tem-se:

$$
q_{Y N}=\frac{1}{2} C_{0} Q 2 \tau m
$$

Em que $q_{\mathrm{YN}}(\mathrm{mg} / \mathrm{g})$ é a capacidade adsorvida do adsorbato por unidade de massa do adsorvente, $C_{0}(\mathrm{mg} / \mathrm{L})$ é a concentração de entrada do adosrvente na coluna, $\mathrm{Q}(\mathrm{L} / \mathrm{s})$ é a vazão volumétrica do efluente, $\tau$ (s) é o tempo para a coluna atingir $50 \%$ da saturação e $\mathrm{m}(\mathrm{g})$ é a massa do adsorvente na coluna.

\section{METODOLOGIA}

\subsection{Síntese da água produzida}

A utilização da água produzida sintética tem como motivação principal o fato de conter uma menor quantidade de interferentes analíticos que pudessem prejudicar os ensaios adsortivos. Os componentes principais da água produzida sintética são: água destilada, cloreto de sódio e querosene comercial. A água foi preparada a partir de uma concentração de 100.000 $\mathrm{mg} \cdot \mathrm{L}^{-1}$ de cloreto de sódio e de $400 \mathrm{mg} \cdot \mathrm{L}^{-1}$ de querosene comercial, de modo a simular uma água produzida com um teor de óleos e graxas próximo à 400 ppm (Gomes, 2009). Devido às perdas de óleo no processo de emulsificação, a concentração de querosene obtida no fim da síntese é menor do que os 400 ppm propostos.

Com o contato de todos os constituintes, a água produzida sintética foi posta em agitação vigorosa no Dispersor SL 115 - SOLAB pelo tempo de 15 minutos. 


\subsection{Determinação da concentração de óleo}

A determinação da concentração de óleo remanescente em meio aquoso será realizada a partir do método desenvolvido por Curbelo (2002). Este método utiliza como princípio analítico a espectrofotometria UV-Vis com a utilização do clorofórmio como fase solvente para a extração do óleo emulsionado.

Primeiramente, faz-se uma curva de calibração utilizando o óleo utilizado e o clorofórmio. Essa curva deverá ser composta por pontos compreendidos dentro da faixa de interesse, ou seja, de 0 ppm e 400 ppm de óleo em clorofórmio. A curva de calibração é importante para que se possa mostrar qual a concentração do óleo na fase aquosa ao fim do processo adsortivo em banho finito a partir do valor da absorbância medida no espectrofotômetro UV-Vis (Curbelo, 2002).

A metodologia de análise consiste em coletar no final dos experimentos $100 \mathrm{~mL}$ do sobrenadante ao fim do banho finito, adicionar $10 \mathrm{~mL}$ de clorofórmio (solvente), com o auxílio de um agitador magnético, agitar por 5 minutos, coletar a fase solvente após a separação das fases, centrifugar a fase solvente durante 2 minutos e ler a absorbância no espectrofotômetro UV-Vis U2M - QUIMIS no comprimento de onda de $260 \mathrm{~nm}$. Com o valor da absorbância, aplicar na curva de calibração para visualizar qual a concentração de óleo no clorofórmio e, consequentemente, na fase aquosa que estava em contato com o adsorvente (Curbelo, 2002).

\subsection{Isoterma de adsorção}

A obtenção das isotermas de adsorção se basearam no método do banho finito. Massas conhecidas de carvão ativado comercial variando entre $0,02 \mathrm{~g}$ a 1,60 g foram postas em contato com $150 \mathrm{~mL}$ de água produzida sintética em um agitador de bancada MARCONI. A temperatura do experimento foi controlada em 25 ㄷ C e o tempo de contato foi de 5 horas.

Com a obtenção da concentração final de equilíbrio do óleo na fase aquosa pode-se calcular o "qExp", que expressa a quantidade de óleo adsorvida por massa de adsorvente. Este parâmetro é comumente expresso em $\mathrm{mg}$ de adsorbato/g de adsorvente:

$q_{E X P}=\frac{V\left(C_{\text {inicial }}-C_{\text {final }}\right)}{m}$

Em que $V(L)$ é o volume da solução, $C_{\text {inicial }}(\mathrm{mg} / \mathrm{L})$ e $C_{\text {final }}(\mathrm{mg} / \mathrm{L})$ são, respectivamente, as concentrações inicial e final de equilíbrio do óleo no meio aquoso, $\mathrm{m}(\mathrm{g})$ é a massa de adsorvente e $\mathrm{q}_{\mathrm{EXP}}(\mathrm{mg} / \mathrm{g})$ representa a massa de óleo adsorvido pela massa de adsorvente. Um gráfico de $\mathrm{q}_{\mathrm{EXP}}$ versus $C_{\text {eq }}(\mathrm{mg} / \mathrm{L})$ é plotado e, assim, tem-se a isoterma de adsorção. Com isso, os modelos de Langmuir e Freundlich foram ajustados aos dados experimentais.

Para o ajuste dos modelos, assim como na determinação dos parâmetros característicos das Equações 1 e 2 para Langmuir e Freundlich, respectivamente, foi utilizado a técnica da regressão não-linear com o auxílio do software Statistica 7.0, de modo a verificar a consistência dos dados com um nível de confiança de $95 \%$. 


\subsection{Curva de ruptura}

Os experimentos foram realizados em temperatura ambiente ( $25 \stackrel{\circ}{\circ}$ ) em um sistema construído mostrado pela Figura 2:

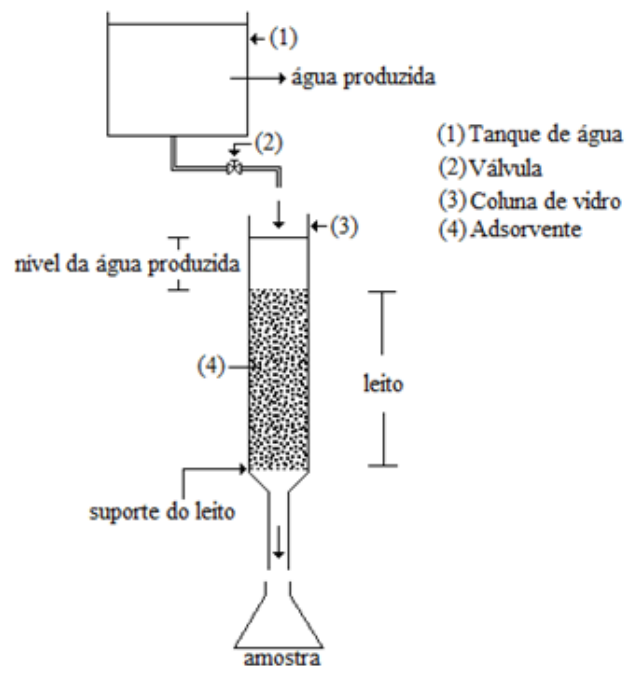

Figura 2: Esquema do experimento de adsorção em leito fixo

A Figura 2 mostra o esquema utilizado nesse experimento; a coluna utilizada foi de vidro e com um diâmetro interno $D$ de $3,2 \mathrm{~cm}$, de modo que se possa obter uma saturação do leito relativamente rápida. No seu interior, colocou-se uma massa conhecida $\mathrm{m}(\mathrm{g})$ do carvão ativado comercial. O sistema foi composto também por um compartimento de alimentação colocado na parte superior da coluna para alimentar o sistema por gravidade e, ao mesmo tempo, possibilitar a manutenção da altura de líquido na coluna, a fim de que o diferencial de pressão fosse mantido constante, o que evita, assim, a formação de caminhos preferenciais.

Alimentou-se a coluna com a água produzida sintética de concentração inicial $C_{0}(\mathrm{mg} / \mathrm{L}) \mathrm{e}$ operou-se com uma vazão volumétrica $Q(\mathrm{~L} / \mathrm{h})$ medida pela base da coluna. Nessa mesma base, a cada 10 minutos coletou-se $100 \mathrm{~mL}$ do efluente tratado para análise no espectrofotômetro U2M - QUIMIS e determinação da concentração de óleo remanescente C $(\mathrm{mg} / \mathrm{L})$, seguindo o mesmo procedimento analítico utilizado para o experimento de banho finito. $O$ procedimento experimental foi conduzido até a obtenção do ponto de ruptura/saturação do leito, ou seja, curva de ruptura.

A partir dos dados de concentração $C_{0}$ e $C$, gerou-se a curva de ruptura do sistema água produzida sintética-carvão ativado comercial. Plotaram-se os gráficos $\mathrm{C} \mathrm{C}_{0}$ (adimensional) versus $V_{\text {TRATADO }}(L)$, de modo a obter os volumes de ruptura $V_{\text {RUP }}(L)$ e de saturação $V_{S A T}(L)$ e $C / C_{0}$ versus $t$ (s), de modo a retirar os pontos do gráfico úteis à geração dos modelos matemáticos de Thomas e Yoon-Nelson.

\subsection{Determinação das capacidades adsortivas (q)}

O valor da capacidade adsortiva do conjunto adsorvente-adsorbato pode ser predito a partir das informações fornecidas pela isoterma de adsorção. Entretanto, o processo em leito fixo nem sempre se desempenha em condições ideais de equilíbrio, como acontece no ensaio de banho finito. Com isso, necessitou-se calcular, além da capacidade adsortiva fornecida pela 
isoterma, as capacidades adsortivas real da coluna e as preditas pelos modelos matemáticos de Thomas e de Yoon-Nelson.

O cálculo da capacidade adsortiva a partir da isoterma de adsorção foi realizado após o ajuste dos modelos aos dados experimentais. Para o modelo de Langmuir, tem-se que a capacidade adsortiva é determinada pela Equação 1. Para o modelo de Freundlich, o cálculo da capacidade adsortiva se dá a partir da Equação 2.

A capacidade adsortiva da coluna foi calculada a partir da obtenção do volume de fluido tratado até a completa saturação do carvão ativado, $V_{S A T}$, como descrito pela Figura 3. Relacionando esse volume à massa de adsorvente presente na coluna e à concentração de entrada do efluente a ser tratado, tem-se a Equação 12:

$$
q_{C O L}=\frac{C_{0} V_{S A T}}{m}
$$

Em que qcol é a capacidade adsortiva da coluna, $C_{0}$ é a concentração de entrada do efluente na coluna, $V_{S A T}$ é o volume de saturação (ou de exaustão do leito) do ensaio em coluna e $m$ é a massa do adsorvente na coluna.

Os modelos matemáticos de Thomas, Equação 8, e Yoon-Nelson, Equações 9 e 10, descrevem o comportamento do processo adsortivo em leito fixo. Em ambos os modelos, os valores da capacidade adsortiva do sistema e as constantes cinéticas são determinadas a partir de uma regressão não-linear dos dados contidos no ponto de ruptura.

\section{RESULTADOS E DISCUSSÃO}

\subsection{Isoterma de adsorção}

Os modelos adsortivos de Langmuir e de Freundlich foram ajustados aos dados experimentais, de modo a investigar qual modelo melhor representa o sistema estudado e se os parâmetros estimados são estatisticamente significativos. A Figura 3 mostra a isoterma obtida:

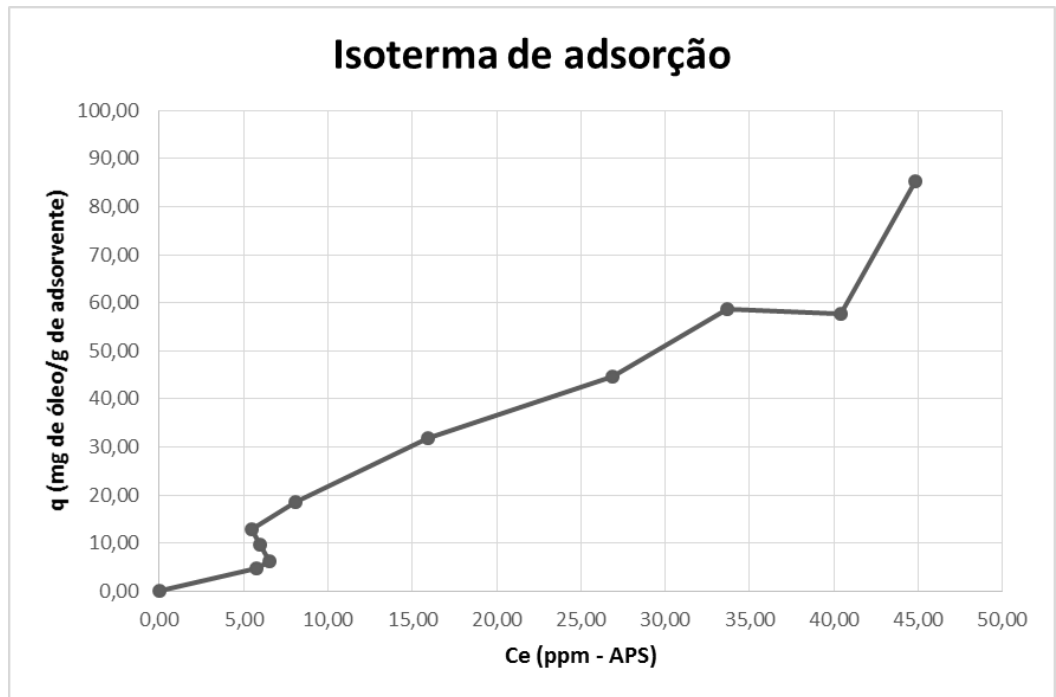

Figura 3: Isoterma de adsorção obtida entre o carvão ativado e a água produzida sintética 
Na Tabela 1, para o modelo de Langmuir, tem-se os seguintes valores para os parâmetros $\mathrm{K}_{\mathrm{L}}$ e $\mathrm{q}_{\mathrm{m}}$, que são, respectivamente, a constante de equilíbrio relacionada com a energia de ligação adsorbato-adsorvente e a constante que representa a quantidade máxima de adsorbato que pode ser adsorvida:

Tabela 1: Valores dos parâmetros $K_{L}$ e $q_{m}$ obtidos a partir da regressão não-linear

\begin{tabular}{c|c|c|c|c|c}
\hline Parâmetro & Valor estimado & Erro padrão & Valor-p & Limite inferior & Limite superior \\
\hline $\mathrm{K}_{\mathrm{L}}$ & 0,00046 & 0,00484 & 0,9261 & $-0,0105$ & 0,0114 \\
$\mathrm{q}_{\mathrm{m}}(\mathrm{mg} / \mathrm{g})$ & 3768,02 & 37668 & 0,9225 & -81444 & 88980 \\
$\mathrm{R}^{2}$ & 0,9796 & & & & \\
\hline
\end{tabular}

A Tabela 1 mostra que o processo adsortivo não segue o modelo de Langmuir, pois, apesar de apresentar um bom ajuste $\left(R^{2}\right)$, as constantes obtidas pela regressão não são estatisticamente significativas. Chegou-se a essa conclusão pelo fato de os valores-p de ambas as constantes serem maiores do que o nível de significância adotado $(\alpha=0,05)$. Além disto, analisando os limites superior e inferior, que representam, de acordo com o nível de confiança de $95 \%$, a probabilidade de onde os parâmetros analisados ( $K_{L}$ e $q_{m}$ ) estão; observa-se que estes limites não são significativos estatisticamente, pois representam um intervalo em que os parâmetros $\mathrm{K}_{\mathrm{L}}$ e $\mathrm{q}_{\mathrm{m}}$ podem ter valores negativos, o que é fisicamente incorreto.

Para o modelo de Freundlich, as constantes a serem determinadas são $K_{F}$ e $n$, que são, respectivamente, as constantes empíricas indicadoras da capacidade e da intensidade da energia de adsorção, como mostra a Tabela 2:

Tabela 2: Valores dos parâmetros $\mathrm{K}_{\mathrm{F}}$ e $\mathrm{n}$ obtidos a partir da regressão não-linear

\begin{tabular}{c|c|c|c|c|c}
\hline Parâmetro & Valor estimado & Erro padrão & Valor-p & Limite inferior & Limite superior \\
\hline $\mathrm{K}_{\mathrm{F}}$ & 1,7250 & 0,6880 & 0,0335 & 0,1687 & 3,2814 \\
$\mathrm{n}$ & 1,0024 & 0,1123 & 0,00001 & 0,7484 & 1,2564 \\
$\mathrm{R}^{2}$ & 0,9960 & & & & \\
\hline
\end{tabular}

$\mathrm{O}$ ajuste do modelo de Freundlich aos dados experimentais foi melhor do que o apresentado por Langmuir. Porém, para poder afirmar que o modelo de Freundlich é, de fato, representativo, observou-se que ambos os coeficientes $\mathrm{K}_{F}$ e $n$ foram estatisticamente significativos. $O$ valor da constante $n$ entre 1 e 10 indica um processo adsortivo favorável.

Okiel et al., (2011) mostraram que, para o sistema óleo-carvão ativado em pó, o melhor ajuste se deu pelo modelo de Freundlich. Os valores das constantes $\mathrm{K}_{\mathrm{F}}$ e $\mathrm{n}$ foram iguais a 10,39 e a 1,51. Para Oliveira et al. (2014) tanto o modelo de Langmuir quanto o modelo de Freundlich se ajustaram bem aos dados experimentais, apesar de não ter havido uma investigação da significância estatística das regressões realizadas. Os valores de $\mathrm{K}_{\mathrm{F}}$ e $\mathrm{n}$ foram, respectivamente, 9,75 e 1,75 . 


\subsection{Curva de ruptura}

Os parâmetros de operação da coluna de leito fixo para a obtenção da curva de ruptura estão descritos pela Tabela 3:

Tabela 3: Parâmetros operacionais da coluna em leito fixo

\begin{tabular}{c|c|c|c|c|c|c|c}
\hline $\mathrm{D}(\mathrm{cm})$ & $\mathrm{C}_{0}\left(\mathrm{mg} . \mathrm{L}^{-1}\right)$ & $\mathrm{Q}\left(\mathrm{L} . \mathrm{s}^{-1}\right)$ & $\mu_{0}\left(\mathrm{~cm} . \mathrm{s}^{-1}\right)$ & $\mathrm{h}(\mathrm{cm})$ & $\rho_{\mathrm{b}}\left(\mathrm{g} \cdot \mathrm{L}^{-1}\right)$ & $\mathrm{m}(\mathrm{g})$ & $\mathrm{t}_{\text {res }}(\mathrm{s})$ \\
\hline 3,2 & 228,5 & $2,42 \times 10^{-3}$ & 0,3 & 1,93 & 516,57 & 8,0068 & 6,40 \\
\hline
\end{tabular}

Em que $D$ é o diâmetro interno da coluna, $C_{0}$ é a concentração inicial de óleo que entra na coluna, $Q$ é a vazão volumétrica de operação, $\mu_{0}$ representa a velocidade superficial, $h$ é a altura do leito, $\rho_{b}$ é a densidade aparente do carvão ativado comercial, $m$ é a massa de carvão utilizada e $t_{R E S}$ é o tempo de contato do fluido com o leito.

O experimento em leito fixo teve como principal objetivo obter a curva de ruptura característica para o sistema água produzida sintética-carvão ativado comercial. A Figura 4 mostra a curva de ruptura $\mathrm{C} / \mathrm{C}_{0}$ versus Volume Tratado:

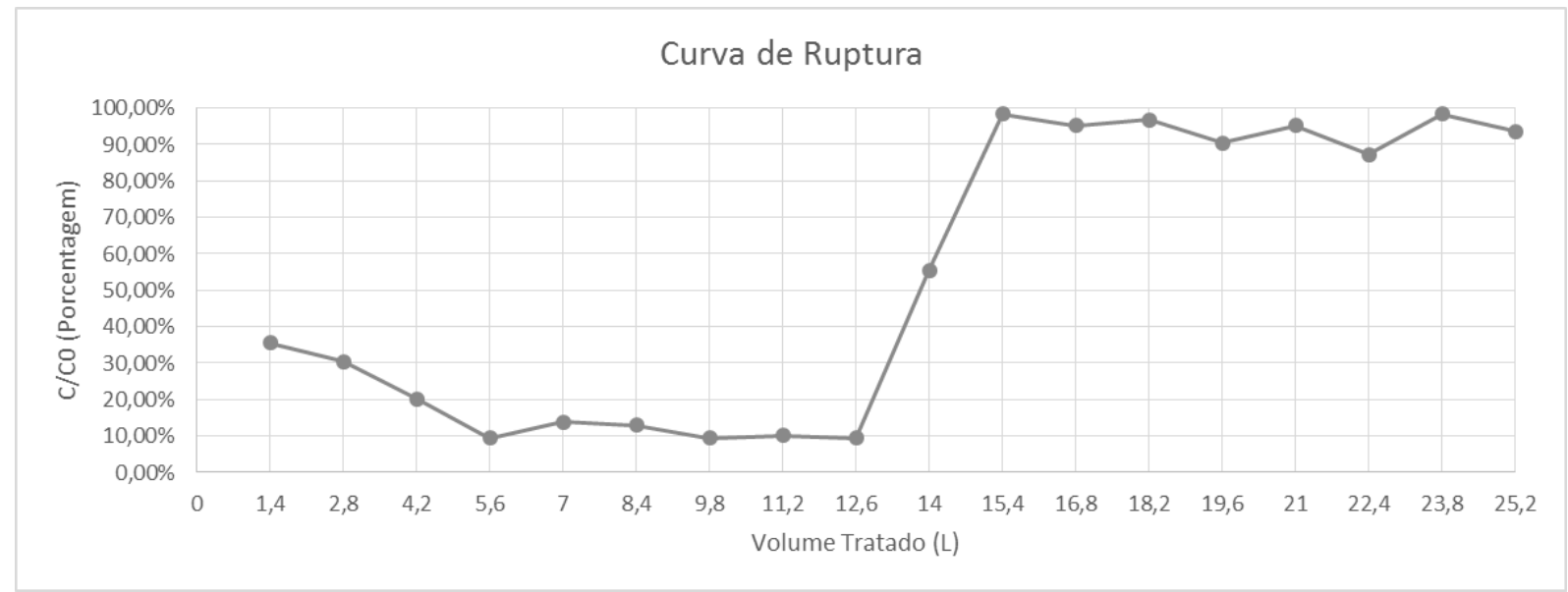

Figura 4: Curva de ruptura " $\mathrm{C} / \mathrm{C}_{0}$ " versus "Volume Tratado"

O formato da curva de ruptura exposta pela Figura 4 segue o que comumente é reportado para sistemas favoráveis ao processo adsortivo. $\mathrm{O}$ formato em $\mathrm{S}$ é tido como padrão na obtenção desses tipos de curva, onde apenas uma classe de componentes é adsorvida pelo adsorvente (Ling et al., 2016; McCabe et al., 1993).

A Figura 4 mostra que a remoção contínua de óleo até a ruptura foi de aproximadamente $90 \%$. O ponto de ruptura foi fixado no ponto $\mathrm{C} / \mathrm{C}_{0}=30 \%$, ou seja, a operação da coluna na prática deve ser interrompida quando a remoção de óleo for igual ou menor do que $70 \%$. Graficamente observou-se que os volumes de ruptura e de exaustão $V_{\text {RUP }}$ e $V_{S A T}$ foram, respectivamente, $13,5 \mathrm{~L}$ e $15,5 \mathrm{~L}$. Já o tempo de ruptura $t_{b}$ foi de $5580 \mathrm{~s}$ e a porcentagem de leito não utilizado foi de $12,90 \%$. 


\subsection{Capacidades adsortivas ( $q$ )}

A capacidade adsortiva demonstrada pela coluna em leito fixo experimental foi calculada pela Equação 12, sendo seu valor igual a $442,34 \mathrm{mg}$ de óleo/g de carvão. A capacidade adsortiva calculada na condição de equilíbrio pela isoterma de Freundlich (Equação 2), a qual obteve-se constantes estatisticamente significativas, foi igual a $389,06 \mathrm{mg}$ de óleo/g de carvão. A proximidade destes valores garante uma coerência em relação ao fenômeno de transferência de massa ocorrido para o sistema estudado. Consequentemente, essa proximidade valida os dados de equilíbrio e a curva de ruptura descrita pelas Figuras 3 e 4, respectivamente.

A partir dos pontos contidos na região de saturação do adsorvente na coluna (Figura 4), calculou-se os parâmetros intrínsecos aos modelos de Thomas e de Yoon-Nelson pelas Equações 8, 9 e 10. A Tabela 4 mostra os valores obtidos para os modelos de Thomas e Yoon-Nelson:

Tabela 4: Parâmetros referentes aos modelos matemáticos

\begin{tabular}{|c|c|c|c|c|}
\hline Modelo & K & $\mathrm{q}_{\mathrm{MOD}}(\mathrm{mg} / \mathrm{g})$ & $\tau(s)$ & $\mathrm{R}^{2}$ \\
\hline Thomas & $2,02 \times 10^{-5}\left(\mathrm{~L} \cdot \mathrm{mg}^{-1} \cdot \mathrm{s}^{-1}\right)$ & 410,30 & ---- & 0,997 \\
\hline Yoon-Nelson & $4,62 \times 10^{-3}\left(\mathrm{~s}^{-1}\right)$ & 410,28 & 5940 & 0,998 \\
\hline
\end{tabular}

As constantes $\mathrm{K}$ inerentes a cada modelo não foram estatisticamente significativas, enquanto que as capacidades adosrtivas $\mathrm{q}_{\mathrm{MOD}}$ e o tempo para a colunar atingir $50 \%$ da saturação $\tau$ foram estatisticamente significativos. Os modelos se ajustaram bem aos pontos experimentais, obtendo-se valores para $\mathrm{R}^{2}$ muito próximos da unidade. Com os parâmetros estipulados, os modelos podem ser usados para a predição do comportamento da curva de ruptura em condições de operação distintas das utilizadas no experimento deste estudo.

Verificou-se que os valores das capacidades adsortivas obtidas pelos modelos em questão foram valores muito próximos. Isto se dá pelo fato de os modelos de Thomas e de Yoon-Nelson serem matematicamente iguais, diferindo apenas no significado das constantes envolvidas. É importante destacar que o valor da capacidade adsortiva predita pelos modelos está próximo dos valores obtidos pela isoterma de Freundlich e pela curva de ruptura, como mostra a Tabela 5:

Tabela 5: Valores obtidos para as capacidades adsortivas da coluna, da isoterma e dos modelos cinéticos, em mg de óleo/g de carvão

\begin{tabular}{c|c|c|c}
\hline$q_{\text {col }}(\mathrm{mg} / \mathrm{g})$ & $\mathrm{q}_{\mathrm{FR}}(\mathrm{mg} / \mathrm{g})$ & $\mathrm{q}_{\mathrm{TH}}(\mathrm{mg} / \mathrm{g})$ & $\mathrm{q}_{\mathrm{YN}}(\mathrm{mg} / \mathrm{g})$ \\
\hline 442,34 & 389,06 & 410,30 & 410,28 \\
\hline
\end{tabular}

Isso mostra uma coerência entre os dados teóricos e experimentais com relação às capacidades adsortivas q obtidas para o sistema água produzida-carvão ativado comercial.

\section{CONCLUSÕES}

1- Os dados experimentais de equilíbrio para o sistema água produzida sintética-carvão ativado comercial foram bem representados pelo modelo de adsorção de Freundlich.

2- A capacidade adsortiva calculada pela curva de ruptura qcol e pela isoterma de Freundilich $q_{F R}$ apresentaram valores próximos, o que indicou uma coerência em relação ao 
fenômeno de transferência de massa ocorrido nos sistemas, validando, assim, os dados de equilíbrio e a curva de ruptura.

3- Os modelos cinéticos de Thomas e Yoon-Nelson representaram satisfatoriamente a região de ruptura para o sistema estudado, pois observou-se uma proximidade entre os valores da capacidade adsortiva predita pelos modelos $q_{M O D}$ e da capacidade adsortiva calculada pela coluna $\mathrm{q}_{\mathrm{COL}}$ e pela isoterma de Freundlich $\mathrm{q}_{\mathrm{FR}}$.

4- No processo em leito fixo foram alcançados percentuais de remoção na ordem de $90 \%$ do óleo presente na água produzida.

\section{REFERÊNCIAS}

Araújo, D. A. (2015). Síntese do bio-óleo através de desoxigenação catalítica de ácidos graxos e derivados com catalisadores $P d / C$. Dissertação de mestrado, Programa de Pós-Graduação em Química, UFPB.

Araújo, W., \& Sobrinho, N. A. (2000). Influência das propriedades físicas e químicas de solos intemperizados na adsorção de chumbo, cobre e zinco. Floresta E Ambiente, 7(1), 167-180.

ARPEL. (2005). Disposal and treatment of produced water, (91).

Bhatnagar, A., Hogland, W., Marques, M., \& Sillanpää, M. (2013). An overview of the modification methods of activated carbon for its water treatment applications. Chemical Engineering Journal, 219, 499-511. https://doi.org/10.1016/j.cej.2012.12.038

Boligon, J. (2015). Produção e caracterização de carvão ativado a partir da borra de café solúvel.Dissertação de mestrado, Programa de Mestrado Profissional em Tecnologia de Alimentos, UTFPR.

Canteli, A. M. D. (2013). Recuperação Do Aroma De Café, Benzaldeído, Em Coluna De Adsorção Utilizando Carvão Ativado. Dissertação de mestrado, Programa de Pós-Graduação em Engenharia de Alimento, UFPR.

Carvalho, P. C. de A. P. (2016). Tratamento combinado da água produzida de petróleo - Filtração, adsorção e foto-fenton. Tese de Doutorado, Programa de Pós-Graduação em Engenharia de Química, UFRN.

Castellan, G. W. (1978). Adsorção sobre sólidos: In Fenômenos de superficie ( $3^{\mathrm{a}}$ ed.). Livros Técnicos e Científicos Editora.

CONAMA. (2005). Resolução n 357, 18 de março de 2005.

CONAMA. (2007). Resolução n 393, 8 de agosto de 2007.

Crispim, S. C. L. (2009). Remoção de Cálcio ( II ) em solução aquosa por meio de carvões ativados submetidos a tratamentos superficiais. Tese de Doutorado, Programa de Pós-Graduação em Química, UFPB.

Curbelo, F. D. da S. (2002). Estudo da remoção de óleo em águas produzidas na indústria de petróleo, por adsorção em coluna utilizando a vermiculita expandida e hidrofobizada. 
Dissertação de mestrado, Programa de Pós-graduação em Engenharia Química, UFRN.

Dabrowski, A. (2001). Adsorption: from theory to practice. Advances in Colloid and Interface Science, 93(1-3), 135-224. https://doi.org/10.1016/S0001-8686(00)00082-8

El-Naas, M. H., Alhaija, M. A., \& Al-Zuhair, S. (2017). Evaluation of an activated carbon packed bed for the adsorption of phenols from petroleum refinery wastewater. Environmental Science and Pollution Research. https://doi.org/10.1007/s11356-017-8469-8

Erdem, E., Karapinar, N., \& Donat, R. (2004). The removal of heavy metal cations by natural zeolites. Journal of Colloid and Interface Science, 280(2), 309-314. https://doi.org/10.1016/j.jcis.2004.08.028

Ferreira, B. H. (2016). Estudo dos processos de tratamento de água produzida de petróleo. Tese de Doutorado, Programa de Pós-Graduação em Engenharia Química, UFRN.

Gomes, E. A. (2009). Tratamento combinado da água produzida de petróleo por eletroflotação e processo fenton.

Gonçalves, M. (2008). Preparação de carvão ativado e impregnação com ferro ou cromo para aplicações em processos de descontaminação ambiental. Tese de Doutorado, Programa de Pós-graduação em Agroquímica, UFLA.

Hernández-Montoya, V., \& Bonilla-Petriciolet, A. (2012). Lignocellulosic precursors used in the synthesis of activated carbon: characterization techniques and applications in the wastewater treatment. InTech, 100. https://doi.org/10.5772/3346

Langmuir, I. (1918). The Adsorption of Gases on Plane Surfaces of Glass, Mica and Platinum. Journal of the American Chemical Society, 40(1914), 1361-1403. https://doi.org/doi: 10.1021/ja02242a004

LeVan, M. D., Carta, G., \& Yon, C. M. (2007). Section 16: Adsorption and Ion Exchange. Perry's Chemical Engineers' Handbook 8/E ( $\left.8^{\mathrm{a}}\right)$. McGraw-Hill. https://doi.org/10.1036/0071511393

Ling, C. P., Ai, I., Tan, W., Lik, L., \& Lim, P. (2016). Fixed-bed Column Study for Adsorption of Cadmium on Oil Palm Shell-derived Activated Carbon, 3(2), 60-71.

McCabe, W. L., Smith, J. C., \& Harriott, P. (1993). Unit Operations of Chemical Engineering (5 Edição).

Morais, J. M. De. (2013). Petróleo em Águas Profundas - Uma história tecnológica da PETROBRAS na exploração e produção offshore.

Nunes, S. K. da S. (2013). Tratamento de água de produção de petróleo visando o aproveitamento na obtenção de barrilha. Tese de Doutorado, Programa de Pós-graduação em Engenharia Química, UFRN.

Okiel, K., El-Sayed, M., \& El-Kady, M. Y. (2011). Treatment of oil-water emulsions by adsorption onto activated carbon, bentonite and deposited carbon. Egyptian Journal of Petroleum, 20(2), 9-15. https://doi.org/10.1016/j.ejpe.2011.06.002

Oliveira, L. H., Scherer Filho, J. A., De Souza, U. A. A., \& Guelli, S. M. A. (2014). Aplicação De 
Carvão Ativado No Tratamento Da Água Produzida Sintética Na Indústria Petroquímica. Anais do COBEQ 2014.

Oliveira, L. R. de. (2014). Remoção De Alumínio Em Sistema Contínuo Por Adsorção Em Coluna De Leito Fixo Com Carvão Ativado. Dissertação de mestrado, Programa de Pós-graduação em Engenharia Química, UFU.

Oliveira, R. C. G. de, \& Oliveira, M. C. K. de. (2013). Remoção De Contaminantes Tóxicos Dos Produção De Petróleo No Mar Removal of the Toxic Contaminants of the Liquid Effluents Derived From the Activity of Oil Production in the Sea. Boletim Técnico - Petrobrás (Vol. 43).

Ray, J. P., \& Engelhardt, F. R. (1992). Produced Water: Technological Environmental Issues and Solutions. Nova lorque: Plenum Press.

Ruthven, D. (1984). Principles of adsorption and adsorption processes. Chemical Engineering and Processing: Process Intensification (Vol. 19). https://doi.org/10.1016/0255-2701(85)80013-1

Santiago, R. C. (2009). Rejeito de xisto como adsorvente para remoção de fenol em águas produzidas na indústria de petróleo. Dissertação de mestrdo, Programa de Pós-Graduação em Ciência e Engenharia de Petróleo, UFRN.

Shukla, A., Zhang, Y. H., Dubey, P., Margrave, J. L., \& Shukla, S. S. (2002). The role of sawdust in the removal of unwanted materials from water. Journal of Hazardous Materials, 95(1-2), 137-152. https://doi.org/10.1016/S0304-3894(02)00089-4

Thomas, H. C. (1944). Heterogeneous Ion Exchange in a Flowing System. Journal of American Chemical Society, 66, 1664-1666.

Thomas, J. E. (2004). Fundamentos de Engenharia de Petróleo ( $2^{\mathrm{a}}$ Ed.). Rio de Janeiro: Interciência - Petrobrás.

Tien, C. (1994). Adsorption Calculations and Modeling. (H. Brenner, Ed.) ( $1^{\mathrm{a}}$ Ed.). Newton: Butterworth-Heinemann Series in Chemical Engeneering.

Voltan, P. E. N., Dantas, A. D. B., Paschoalato, C. F. R., Di Bernardo, L., Voltan, P. E. N., Dantas, A. D. B., ... Di Bernardo, L. (2016). Predição da performance de carvão ativado granular para remoção de herbicidas com ensaios em coluna de escala reduzida. Engenharia Sanitaria $E$ Ambiental, 21(2), 241-250. https://doi.org/10.1590/S1413-41522016138649

Werlang, E. B., Schneider, R. de C. de S., Rodriguez, A. L., \& Niedersberg, C. (2013). Produção de carvão ativado a partir de resíduos vegetais. Revista Jovens Pesquisadores, 3(1), 156-167.

$\mathrm{Xu}$, Z., Cai, J.-G., \& Pan, B.-C. (2013). Mathematically modeling fixed-bed adsorption in aqueous systems. Journal of Zhejiang University-SCIENCE A (Applied Physics \& Engineering), 14(3), 155-176. https://doi.org/10.1631/jzus.A1300029

Yoon, Y. H., \& James, N. H. (1984). Application of gas adsorption kinetics - Part I. A theorical model for respirator cartridge service life. The American Industrial Hygiene Association Journal, 45(8), 509-516. https://doi.org/10.1080/152986684914 00197 